\title{
Medical Image of the Week: Acute Aortic Dissection
}

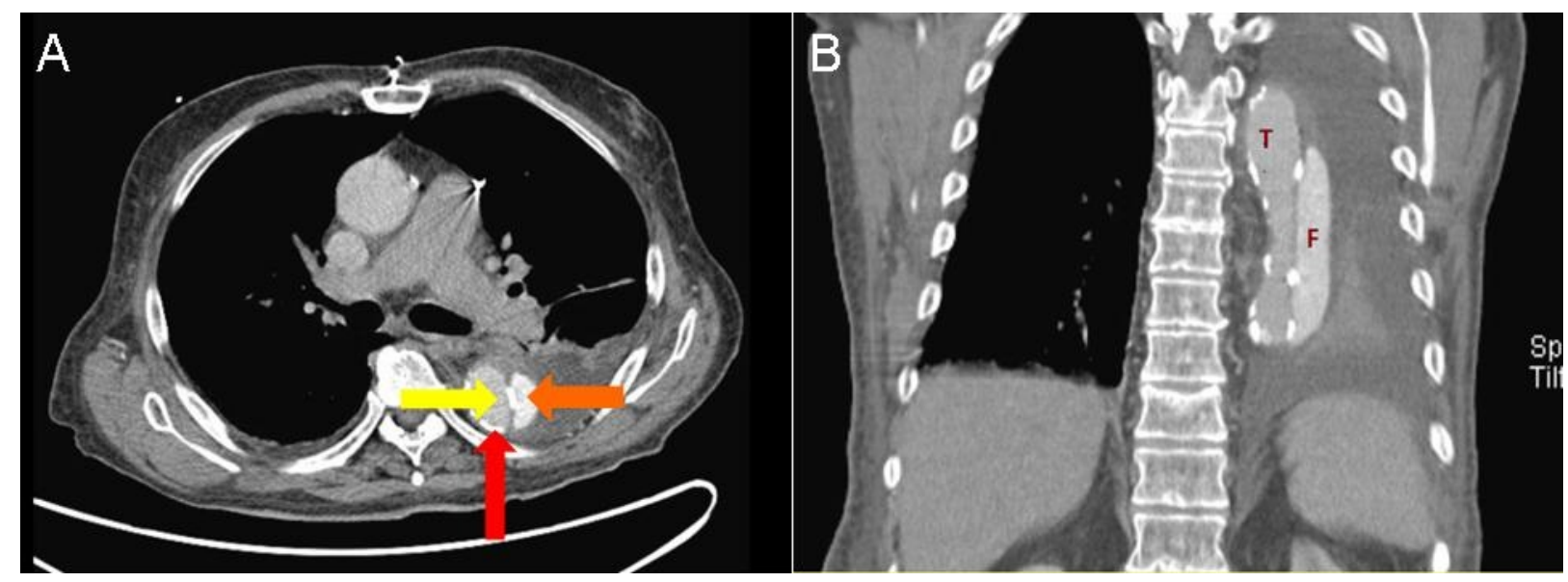

Figure 1: Panel A: Axial view of the thoracic CT angiography showing aortic dissection in descending aorta where the true lumen (yellow arrow) with outer-wall calcification (red arrow) as well as false lumen with contrast (orange arrow) is seen. Panel B: Coronal view showing the true $(T)$ and false $(F)$ lumen.

An 85-year-old gentleman with the past medical history significant for hypertension, smoking, and coronary artery disease presented to the emergency department (ED) with complains of sudden onset of chest pain. His pain was described as squeezing and radiating to the back, associated with nausea and vomiting. His chest pain improved with nitroglycerin in ED. Chest x-ray showed a tortuous aortic knob and widened mediastinum.

He underwent a CT angiogram, which showed, Stanford Type B aortic dissection, from distal aortic arch to renal arteries (Figure 1). He was managed in the hospital conservatively with tight blood pressure control given the type of dissection and no surgical intervention was done. He was uneventfully discharged with follow up arranged with vascular surgery.

Aortic dissection is classified by Stanford Criteria as Type A which involves the ascending aorta and arch and Type B when it involves the descending aorta. Type A dissection is a surgical emergency and guidelines suggest medical / non-surgical management for Type B dissection except in cases where the pain is not controlled despite BP control, acute expansion of the false lumen, peri-aortic hematoma or distal mal-perfusion.

Hem Desai MD ${ }^{1}$, Aung Bajaj MD ${ }^{1}$, Kamalani Hanamaikai MD ${ }^{1}$ \& Bhupinder Natt $\mathrm{MD}^{2}$ ${ }^{1}$ Department of Internal Medicine and the ${ }^{2}$ Division of Pulmonary, Allergy, Critical Care and Sleep Medicine

University of Arizona

Tucson, AZ USA 


\section{References}

1. LePage MA, Quint LE, Sonnad SS, Deeb GM, Williams DM. Aortic dissection: CT features that distinguish true lumen from false lumen. AJR Am J Roentgenol. 2001;177(1):207-11. [CrossRef] [PubMed]

2. von Kodolitsch $Y$, Nienaber CA, Dieckmann C, Schwartz AG, Hofmann T, Brekenfeld C, Nicolas V, Berger J, Meinertz T. Chest radiography for the diagnosis of acute aortic syndrome. Am J Med. 2004;116(2):73-7. [CrossRef] [PubMed] 